\title{
Moving Image Helps Explore Potential Stories Based on the Calendar Posters of Shanghai from the 1920s to 1940 s
}

\author{
Xinxin Xiu \\ Department of Digital Arts \\ Dalian Neusoft University of Information \\ Dalian, China
}

\author{
Bin Wang \\ Department of Digital Arts \\ Dalian Neusoft University of Information \\ Dalian, China
}

\begin{abstract}
The problem of how moving image could help explore potential stories based on the calendar posters of Shanghai from 1920s to 1940 s will be discussed during this paper. This is a matter of carinal significance in analyzing and studying systematically through three parts: the calendar poster of Shanghai, potential stories based on reading images and graphic moving image in communication. The impacts of our obtained results are attracting viewers through moving images, as a popular way of demonstration, and then telling them what the Shanghai calendar posters are. What is more, more worldwide spectators appreciate those vintage posters in the gallery and museum; more colorful stories are imagined and created from various cultures to deliver Chinese culture of posters.
\end{abstract}

Keywords - moving image; calendar poster; potential stories; old Shanghai

\section{INTRODUCTION}

The research question of how Moving Image could help explore potential stories based on the calendar posters of Shanghai from the 1920s to 1940s will be discussed during this paper. The calendar poster of Shanghai, called Yuefenpai in Mandarin, most of which feature the portraits of classic beauties, is one form of product advertising, which appeared from the late 19th century in the city of Shanghai and flourished in the early 20th century. This kind of poster is rooted in a special historical background in colonial Shanghai. "In the 1920s and 1930s, with the metropolis of Shanghai acting as a clearing-house for western imports, a thoroughly modern approach to graphic design evolved, known as the "Shanghai style". So during this period, much westernization was absorbed by Chinese traditional graphic design and built the new aesthetic standard, promoted in posters, and it still remains recognizably Chinese. My research question could immediately highlight my directions of focusing on the calendar posters of Shanghai, moving images and potential stories.

\section{THE CALENDAR Poster OF SHANGHAI}

\section{A. Historical Background of Shanghai}

At the beginning of the 20th century, the change across the whole world in aspects of technology, economy, culture and ideology was unprecedented. With applying new modes of production, revolution began in various fields. The world developed rapidly during this period, which not only was a turbulent and confusing time, but also a vibrant and exciting era. At the same time, there was a city in the Far East, as the centre of China, the country that the one of the world's oldest cradles of civilization, experiencing an unprecedented ordeal of development. Although it was under Colonial Rule by western countries, it became "the first Chinese city to substantial graphic design industry".

From the first half of the 19th century, some of developed capitalist countries such as Great Britain, the United States, France, Germany, Russia, Denmark, Italy, Portugal, Austria, Spain and Japan began to build the Shanghai International Settlement. Meanwhile, they aggressed on various aspects from economy, politics, culture, and business etc. Old Shanghai was influenced and impacted directly and indirectly by western countries, which gave rise to continually increasing cultural and economical exchange and boom. According to the report of scholar Ming $\mathrm{Ni}$, named 'The design of old Shanghai Calendar posters', China had to open up five coastal cities, one of which is Shanghai as the 'trade port', where foreigners were allowed to live and work after the Opium Wars and the Treaty of Nanking of 1842. After it was opened as the port for foreign countries, business developed rapidly, especially in the fields of international trade and marine transportation. Therefore, various Shanghai calendar posters gradually formed and developed under such a historical background in the Strong collision between Chinese and Western culture.

\section{B. What is the Calendar Poster of Shanghai?}

With the gradual western integration in the fields of politics, economy and culture in Shanghai, the Shanghai calendar posters, as a branch of the lunar New Year pictures art (nianhua in Mandarin), started in people's daily lives. The calendar posters of old Shanghai, usually called Yuefenpai in Mandarin, were the Chinese type of product advertising which appeared from the late 19th century in the city of Shanghai and flourished in the early 20th century, most of whom were used commercially to promote the western goods such as cigarettes, medicine, perfume and wine. "In the 1920s and 1930s, with the metropolis of Shanghai acting 
as a clearing-house for western imports, a thoroughly modern approach to graphic design evolved, known as the "Shanghai style". Designers of calendar posters reflected the environment and lifestyle of that era through images from calendar posters. As for subjects of calendar posters, most of them were about modern young women, religion, nature, and Chinese traditional opera stories or folk culture. Especially, beautiful young women in the metropolitan city were the most popular theme.

Generally, the typical calendar posters of Shanghai have 6 main elements.

- The subject of posters, called 'central pictures', in the middle or centre of the posters.

- The calendar is always located on the bottom or the two sides:

- The name of the product or company is at the top of the pictures;

- Logo of the company;

- The relevant text information, such as advertising text and promotional information;

- The rectangular frame is like the frame of traditional ink art with decorative function.

Those are all examples of elements that are typically part of the calendar posters of Shanghai.

Initially, the calendar and product advertising of western companies were printed in a calendar poster, and then provided to the public for free. The reason why western businessmen did the calendar posters that was they found a traditional custom that Chinese were used to hanging lunar New Year pictures on the walls of their homes. In 1896, the first calendar poster that was decorated with a beautiful brush rubbed picture and calendar appeared in the Qing Dynasty. A bank, called Hongfulai, issued a lottery ticket, titled "Colourful Scenes of Shanghai: Chinese and Western Calendar". Spreading widely, the calendar poster had not just been an advertisement, but also it was seen as one kind of medium through which the masses gained updated information on politics, economy, culture, history, entertainment, fashion, arts and ideas.

Calendar posters of shanghai have three main values:

- The value of history

- The collectible value

- Artistic research value

The Shanghai calendar poster was the symbol that was the beginning of the modern Chinese advertising industry. The first prototype of the advertising company was established at this period. In 1925, a famous painter of the calendar posters, named Zhiying Hang, built the "Hang Zhiying Studio", specializing in advertisement posters and product design. The majority of the collectors found the collectible value due to the auction price of the Shanghai calendar poster are higher and higher. One of the collectors is Alan Chan, a well-known designer in Hong Kong, who is pretty crazy about collecting old Shanghai's calendar posters of the 1930s. However, he does not just focus on the price, but also the artistic research value. There is an increasing number of designers and research scholars fascinated by old Shanghai's poster arts, and they have been exploring applications of Shanghai style. For instance, in Mainland China Lihong Wang, who is a scholar from Nanjing Arts Institute, issued a paper on 'the Inspiration of Calendar Art of Old Shanghai to the Design of Commercial Posters Today'. She completely and systematically analyzes the potential development of calendar posters, which also provides the theoretical basis for my study.

\section{The Relationship between the Calendar Posters and Art Deco}

This type of Shanghai style (Shanghai calendar posters) absorbed Realistic western drawing style and figure compositions from Renaissance Art, Art Nouveau and Art Deco, as the same time continuing Chinese traditional drawing skills of lunar New Year pictures. However, Art Deco had a profound effect on "Paris of the East" - Shanghai, especially for calendar posters.

Art Deco, 'Sometimes known as 'Jazz Moderne' or simply 'moderne'." starting 1908s and gradually declining after the 1930s, was the dominant style of the 1920s and 1930s, which overlaps completely with flourishing period of Shanghai calendar posters. It "like its forerunner Art Nouveau, was an eclectic style." combining ancient artistic elements \& techniques and mechanical aesthetics \& modern expression. Symbolic features of Art Deco style were: exotic, colourful, sometimes even ashy and vulgar. Those were based on geometric shapes and stylized natural forms, and using luxurious materials. Art Deco style embraced various fields, not only in the field of fine and decorative arts, but also in packaging, posters, product design, fashion, film, photography, architecture, interior decoration, furniture, fabrics, stage design.

The influences to calendar posters of Shanghai from Art Deco style are demonstrated mainly in the aspects of fashion, photography and film. Firstly, the fashion design of women was flourishing with an upward tendency of feminism at the beginning of the century in western countries. While a large number of calendar posters' subjects were beautiful women, so aspect of fashion design produced the most important impact on the development of calendar posters in the whole period of Art Deco. Costume as a medium for the arts shows the ethos of Art Deco, especially in patterns of the qipao. Paul Poiret who was the first fashion designer to embrace the spirit of Art Deco established the foundations of modern fashion. His designs demonstrated "bright, acidic hues and used strong juxtapositions of motifs, details and ornaments derived from folk art or combing stylized oral devices and geometric lines." Those features can be found in some calendar posters, in which modern women wore the reformational qipao. What is more, an increasing number of clothes, woolen cloth, yarn and other materials with different patterns in Art Deco style were imported into Shanghai, which made qipao's pattern and fabric more diverse. In 
addition, Art Deco style not only had influences on the pattern and fabric in reforming qipao, but also on clothing style. The style of concise and modern costume was a major milestone of Art Deco in the field of fashion and new style was used in designing the costume of modern women in calendar posters.

As an international style, the influence of Art Deco was not limited in fashion to the calendar poster of old Shanghai but also included photography and film, significantly, on design principles and skills, such as layout, colouring and perspective arrangement. In photography, many designers of calendar posters were photographers or worked in a photo studio on designing stages or painting stage sets because of the introduction of photographic technology from the west. During 1920s and 1940s, with established photographic magazines, an increasing amount of updated information and news could be acquired from magazines, no matter those published in China or overseas, as raw materials or inspiration for creating. Furthermore, the application of the photograph's visual language made calendar posters more vivid and real. Film swept over Shanghai in the early 20th century. Influenced by Hollywood's film stars, there were Chinese film stars coming out such as Hu Die, Lingyu Ruan, and While Li. Designers based on those film stars who led Chinese fashion trends to paint some of modern women in calendar posters. Furthermore, designers also gained inspiration directly from films. For instance, Zhiying Hang who was a famous Chinese designer in old Shanghai and elevated to the "Avant Garde of Modern Design" in China applied bright colour after watching Disney animated movies. Finally, as one important type of graphic design, film posters were popular in Shanghai. The layout and bright colour from film posters also had been referenced by some designers of calendar posters and applied in the field of design and painting.

\section{READ THE CALENDAR POSTER EXPLORE POTENTIAL STORIES}

\section{A. Read Image}

John Berger through out his book 'Ways of Seeing' points out that when viewers see, during exploring the layers of meaning within paintings, graphic art, photographs, even moving images, they are not just looking - they are reading the language of image.

Firstly, the public had better know how an image is read by audiences. Through the system for reading textual and visual combination built by Barthes, which comprises three separate levels, the generation of meaning in the process of visual communication can be seen clearly through this system. The linguistic message, as the first level, is the text itself. The linguistic message ought to produce an important influence on delivering information, which requires a previous knowledge of the particular language employed. "The linguistic message can also carry a second-order signifier by implication". The second level is described as the coded iconic message, which is "a symbolic message and works on the level of connotation". For example, when viewers read that poster of a sexy girl taking a boat with an umbrella, somebody might interpret that as sex, passion, attraction or charm. Contrastingly, others might think about evil or shame, because "what we see is always influenced by a whole host of assumptions concerning the nature of beauty, truth, civilization, form, taste, class and gender". The third message is the non-coded iconic message, which works on the level of denotation. The denotative meanings of an image are fairly easy to decode, such as a woman or a girl. And viewers can look at the picture of a girl and see that it is a girl and not a man or a toy. Although the second and third messages are different levels, they cannot be separated due to reading at the same time by beholders.

\section{B. On Spectators and Interpretations}

However different spectators may read different meanings, even though they view the same image, which is like that William Shakespeare mentioned that there are a thousand Hamlets in a thousand people's eyes, because they read and interpret images based on their preferred meanings.

When the preferred meanings are interpreted by spectators, they become preferred reading. "Sign is potentially transformable into more than one connote configuration", which shows meanings of signs are multiple and complex, and viewers prefer to choose the meaning they like according to Hall mentioned that "the different areas of social life appeared to be mapped out into discursive domains, hierarchically organized into dominant or preferred meanings". So visual images, like the calendar posters of Shanghai, catch the gazes of viewers, and then the viewers re-think and re-innovate their interpretations.

\section{GRAPHIC MOVING IMAGE IN COMMUNICATION}

\section{A. Storytelling through Moving Image}

In the previous section, Viewers imagine and create various stories through re-thinking and re-innovation based on one image. If these stories are demonstrated vividly through moving image viewers not only imagine the stories in their brain, but they could share them with more people, which give the new lives to the old posters. It is worth discussing how to tell a story which is affected by many factors using moving image to the audience clearly, such as aspects of framing of scenes, shots etc. Two aspects will be introduced: one is montage and another is sound effects.

"Montage refers to how the shots of a film are put together". The montage of a moving image is about which type of cut and how to control the rhythm of cuts. Images are edited to be the "continuity cutting". "Shots are edited in order to allow the clear development of the story and to maintain a realistic representation of the spaces which the narrate occupies. There are various ways to establish shots to illustrate place and characters through cutting, such as fade, dissolve, iris and jump. There is an example of jump cuts. One image ends as a girl who wears yellow clothes and the next shot starts with a yellow butter fly, which may produce the connection that this butter fly denotes the girl.

Producing the effect on the development of story is not only in how to put the shots together but also influenced by how long the shot lasts. 
"The rhythm of cuts, determined by how long each shot is held, may also be important in considering a film's effect.". Filming a series of shots, generally, applying many short shots may arouse the mood of intention due to fast switching. Contrarily, applying long shots may produce different moods. Therefore, it is good to develop stories that short shot and long shot were cut alternately.

The sound is also important to most films. Accompanying with images, the sound not only records the real sound of environment and makes the special atmosphere, but also modifies and improved images. "There are three types of sound: environmental, speech and music". Using environmental sounds can make noise effects, which improves the authenticity of the moving image, such as the noise of the crowd and the noisy sound of traffic. Generally, this is the fundamental sound effect. Speech is the dialogue or monologue, which promotes the development of a story.

The music soundtrack is the third sound effect, which can make the atmosphere and express people's emotions such as the sorrow or happiness. For instance, Chinese jazz, same as the calendar poster of Shanghai, originated and developed under the historical background in the strong collision between Chinese and Western culture so it has special feeling of the time played through the gramophone. The music that is full of features of old Shanghai, accompanied the calendar posters may bring the audience back to that age of Shanghai.

\section{B. Advantages of Moving Image in Communication}

With the rapid development of digital technology, the moving image has been playing an important role in conveying information. The moving image still follows the basic principle of graphic design but the concept of timeline is added into moving image; so during the process of conveying information, the moving image usually produces a stronger visual effect. For example, the girl in a motionless calendar poster started blinking her eyes, which may seem as be alive.

There are three main advantages in communication through the moving image. First of all, the moving image can attract attentions of the audience immediately. For example, an advertisement on a web page may include some movement in order to attract the user's attention. This can become a visual irritant. Especially, for the young, they may not have patience to appreciate the calendar posters of Shanghai for a while, but they may be interested to watch one piece of video about a story of the poster.

Secondly, during the process of communication, the moving image usually includes video and audio; we also can call them visual image and sound effect. That means the audience's ears and eyes are accepting the information at the same time. Therefore, in the aspect of information acceptance, moving image is usually better than traditional graphic image.

The last but not the least, communication through moving image is wider, more convenient and effective in contemporary society, which can satisfy the demand of the contemporary audience. Obviously, the screen is the medium of moving image in conveying information. And screens are filled with modern people's lives in different ways, such as TV, computers, smart-phones and various frame medias. Accompanying the development of these "black mirrors", the moving image has been walking into modern people's lives.

\section{CONCLUSION}

All in all, the renaissance of vintage style does not mean totally copying the past: it should be about re-thinking and re-invention. Christopher Gable (one founder of Demeter Fragrance Library) has said "we've got one eye on the present and one on the retro past." Different eras have different elements, no matter in aspect of image or music. For people who have come through the era, these elements or stories somewhat formed a memory in their minds. For people who have not come through that era, they might look forward to their golden age and imagine what stories could happen, but at first such a golden age should be noticed, which means catching the gazes of spectators might be done as the first step. While moving images, as a popular way of demonstration, may attract viewers through vivid video and then tell them what the Shanghai calendar posters are. More worldwide spectators appreciate those vintage posters in the gallery and museum; more colourful stories are imagined and created from various cultures. That is the answer to how moving image could help explore potential stories based on calendar posters of old Shanghai.

\section{ACKNOWLEDGMENT}

I would like to thank all the people who help me during the development of my report, especially Yadan Zhao who support me in writing and spirit. I would also like to give special thanks to all of my tutors - Penny Hilton and Dave Daniels, my colleagues who gave me precious feedback and advice during the whole process.

\section{REFERENCES}

[1] Aynsley, J, "Pioneers of Modern Graphic Design". London: Octopus Publishing Group Ltd, 2004.

[2] Berger, J, " Ways of seeing: based on the BBC television series with John Berger". London: British Broadcasting Corporation. London: Penguin, 1972.

[3] Cheuk, PT, "Chinese Woman and Modernity: Calendar Posters of the 1910s-1930s”. Hong Kong: Joint Publishing., 1996.

[4] Crow, D, "Visible signs: an introduction to semiotics in the visual arts". Lausanne: AVA, 2010.

[5] Helfand, W H \& Ittmann, J, "Health for Sale: Posters from The William H. Helfand Collection”. New Haven\& London: Philadelphia Museum of Art\& Yale University Press, 2011.

[6] Leighton, T, “Art and the moving image : a critical reader". London: Tate Publishing, 2008.

[7] Walter, S, R.J, "Motion blur: onedotzero: graphic moving imagemakers". London: Laurence King Publishing Ltd, 2004.

[8] Rose, G, "Visual methodologies: an introduction to the interpretation of visual materials". Los Angeles ; London : SAGE, 2007.

[9] Song, J, "Lao Yuefenpai". Shanghai: shanghai huabao chuban- she, 1997.

[10] Trunk, J, "The Music Library-Graphic Art and Sound". London: FUEL Publishing, 2005. 